\title{
Impact of DG Configuration on Maximum Use of Load Supply Capability in Distribution Power Systems
}

\author{
Hong Liu, ${ }^{1}$ Yinchang Guo, ${ }^{1}$ Shaoyun Ge, ${ }^{1}$ and Mingxin $\mathrm{Zhao}^{2}$ \\ ${ }^{1}$ Key Laboratory of Smart Grid, Tianjin University, Ministry of Education, Tianjin 300072, China \\ ${ }^{2}$ China Electric Power Research Institute, Beijing 100192, China \\ Correspondence should be addressed to Hong Liu; liuhong@tju.edu.cn
}

Received 23 January 2014; Revised 29 April 2014; Accepted 12 May 2014; Published 27 May 2014

Academic Editor: Hongjie Jia

Copyright (c) 2014 Hong Liu et al. This is an open access article distributed under the Creative Commons Attribution License, which permits unrestricted use, distribution, and reproduction in any medium, provided the original work is properly cited.

\begin{abstract}
Traditional distributed generators (DGs) planning methods take network loss minimization as the main objective to optimize DG sites in feeders. The use of load supply capability (LSC) in DG planning will precisely answer the questions how many DGs should be integrated, which transformer they should be connected to, and which type of DGs should be adopted. The main work of this paper is to analyze the impact of DGs on LSC so as to answer the three key questions. It resolves the planning problem through three steps: (i) two LSC models considering DGs' access are developed, in which two different transfer strategies are considered: direct load transfer and indirect load transfer; (ii) the method of combined simple method and point estimate method is proposed. At last, based on a base case, when the configuration of DGs is changing, the impact of DGs on system LSC is studied. After the case study, the conclusion concerning the impact of load transfer strategy, DG capacities, and DG types on LSC is reached.
\end{abstract}

\section{Introduction}

Distributed generation (DG) is widely used in the distribution power system nowadays in order to take its advantages of cleaner energy, less loss, and local power supply. However, there are many problems such as intermittency, bidirectional power flow, and controlling strategy, coming along with the DG integration. The problems have challenged the traditional network planning [1,2], simulation [3], and protection [4]. In order to solve the planning problems, new planning methods of DGs are needed, which include DG sites and network restructuring. Unfortunately, nearly all of these methods have a common objective of minimizing network losses with reasonable network structures.

The concept of load supply capability (LSC) [5-7], which describes how much demand a system can safely supply, was put forward to evaluate the reliability and economy of distribution systems. It provides a new tool for traditional power system planning particularly for complementing DG planning.

At present, researches that apply LSC into DG planning are not very common. Reference [8] proposes a series of indexes to evaluate the load capability of the distribution power network with DGs. Monte Carlo simulation is used in this research to deal with the uncertainties in DG output and load demand. The method in this paper is well used to evaluate the load capability of one feeder with DGs, but it does not take N-1 network contingency into consideration. Reference [9] presents an N-1 restoration model to evaluate the load transfer capability, which considers the connection of different feeders. In this model, loads can be transferred through breaker actions when one feeder fails. But, it is applicable to the situations when N-1 contingency occurs on HV transformers.

As a result, an LSC evaluation method that considers N1 contingency of transformers is necessary in DG planning. In it, the main impacts of DGs on LSC include DG types, DG capacity, and the transformer DGs are connected to, but the sites of DG in feeders have very little impact on LSC. Therefore, it can decide how many DGs and what types of DGs can access into the power system and which transform they access to according to LSC analysis. Then the detailed sites of DGs can be determined with traditional planning methods considering network losses. The process mentioned above is shown in Figure 1. 


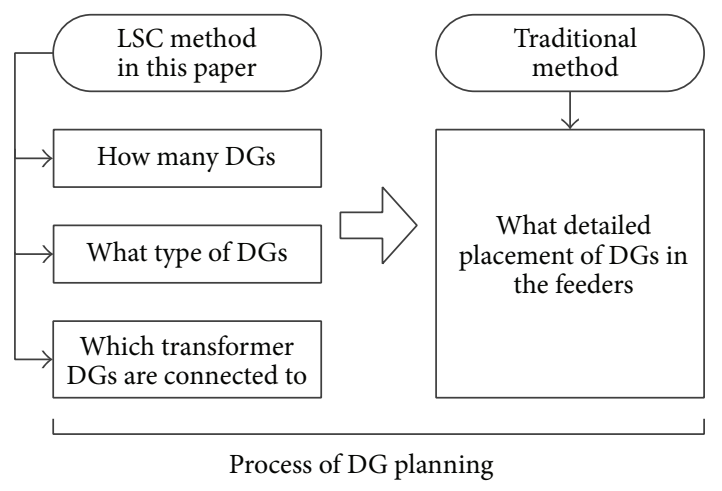

FIgure 1: The relationship between LSC and traditional DG planning.

This paper presents a novel model of LSC considering the access of DGs and then investigates the impact of DGs on LSC. The proposed approach is extremely valuable for DG planning. The main types of DGs in wide use, including photovoltaic (PV), wind turbines, and storage as supplement, are analyzed in this paper.

\section{Concept of Load Supply Capability}

2.1. N-1 Contingency in Distribution Power Systems. When there is one unit (such as transmission lines, substations) lost, the system should immediately restore to supply the demand.

Under N-1 contingency, the lack of supply capacity needs to be filled by neighbor spare units. As a result, the spare capacity is indispensable to satisfy the system operation consistently. The quantity of spare capacity decides the incremental cost because inadequate spare capacity leads to the discrepancies of N-1 contingency while overfull one leads to large-scale investment. To resolve the dilemma, the concept of load supply capability is introduced.

2.2. Load Supply Capability. Under the requirement of N-1 contingency, the total load that the distribution power system can supply is defined as its load supply capability (LSC). Accordingly, LSC in the distribution system is decided by loading factors and the spare capacity of all units in the system.

2.3. LSC Considering DGs. The LSC in the distribution power system increases with DG integration, but the incremental LSC is random because of DGs' intermittency.

2.4. Load Transfer Inner Substation and Load Transfer Intersubstations. As discussed earlier, the proper spare capacity, which is influenced by the load restoration in N-1 contingency, determiners the LSC of a system. Thus, the process in which the loads of one transformer are restored by another is defined as load transfer. Inner substation load transfer is initiated first when the failed and the functional transformers are in the same substation. It is followed by intersubstation load transfer, when the failed and functional transformers are in different substations.

\section{Modeling and Solving Method}

3.1. Capacity of DG Route. To model LSC, it is necessary to build a proper description of DGs. It is found that DGs could be treated as an intermittent supply unit in calculating LSC to transfer load impacted by unit failure for calculation efficiency. So, the concept of DG route is defined.

DG Route. DGs are treated as routes to transfer loads impacted by component failure, so they are defined as DG route in this research. The maximum load capacity that one DG route can transfer is defined as DG route capacity which is probabilistic because of the intermittency of most DGs. In this paper, the main DG types considered are wind turbines, $\mathrm{PV}$, and storage. They will be modelled in detail in the following part.

Turbine output curve [10] is used to describe wind turbines' influence on DG routes. Turbine output curve is a test curve about the relation of real-time wind speed and the output of wind turbine. The curve shows that the output is equal to rated value $P_{r}$ when the wind speed exceeds the cutout speed $V_{\text {co }}$, and it is 0 when the wind speed is smaller than the cut-in speed $V_{\mathrm{ci}}$. If the wind speed is between $V_{\mathrm{ci}}$ and $V_{\mathrm{co}}$, the output is directly proportional to wind speed, shown in

$$
P= \begin{cases}0, & 0 \leq V \leq V_{\mathrm{ci}} \\ \left(A+B \times V+C \times V^{2}\right) P_{r}, & V_{\mathrm{ci}} \leq V \leq V_{r} \\ P_{r}, & V_{r} \leq V \leq V_{\mathrm{co}} \\ 0, & V \geq V_{\mathrm{co}}\end{cases}
$$

where $A, B, C$ are all fitting coefficients of the curve's nonlinear part.

Weibull distribution [11] as given in formula (2) is used to generate wind speed:

$$
f(v)=\frac{k}{c} \cdot\left(\frac{v}{c}\right)^{k-1} \cdot \exp \left[-\left(\frac{v}{c}\right)^{k}\right]
$$

where $v$ is the wind speed and $k$ and $c$ are shape coefficient and scale coefficient.

The PV modelling is similar to wind turbine modelling. The output of PV is decided by solar radiation [12], as shown in

$$
P= \begin{cases}P_{s n}\left(\frac{G_{b t}^{2}}{\left(G_{s t d} R_{c}\right)}\right), & 0<G_{b t}<R_{c} \\ P_{s n}\left(\frac{G_{b t}}{G_{s t d}}\right), & R_{c}<G_{b t}<G_{s t d} \\ P_{s n}, & G_{b t}>G_{s t d},\end{cases}
$$

where $P_{s n}$ is rated power of PV; $G_{s t d}$ is rated solar radiation of $\mathrm{PV}\left(\mathrm{kW} / \mathrm{m}^{2}\right) ; R_{c}$ is the solar radiation value from which the curve becomes linear; and $G_{b t}$ is real-time solar radiation. 
Beta distribution [12] in the following formula is used to generate solar radiation:

$$
f(r)=\frac{\tau(\alpha+\beta)}{\tau(\alpha) \tau(\beta)} \cdot\left(\frac{r}{r_{\max }}\right)^{\alpha-1} \cdot\left(1-\frac{r}{r_{\max }}\right)^{\beta-1},
$$

where $r$ and $r_{\max }$ are real-time solar radiation and maximum solar radiation in a period; $\alpha$ and $\beta$ are shape coefficients of Beta distribution; and $\tau$ is Gamma function.

Energy storage is an essential supplement to DGs. In this research, lead-acid battery is considered. The output of a lead-acid battery is determined by its state of charge. Kinetic Battery Model (KiBaM) $[13,14]$ describes this relation, shown in

$$
\begin{aligned}
& P_{d \max }=\min \left(P_{\mathrm{dkbm}}, P_{\text {misoc }}\right) \eta_{d}, \\
& P_{\mathrm{dkbm}}=\frac{k Q_{1} e^{-k \Delta t}+Q k c\left(1-e^{-k \Delta t}\right)}{1-e^{-k \Delta t}+c\left(k \Delta t-1+e^{-k \Delta t}\right)}, \\
& P_{\text {misoc }}=\frac{Q_{\text {max }}\left(\operatorname{Soc}_{s t}-\text { Soc }_{\text {min }}\right)}{\Delta t},
\end{aligned}
$$

where $P_{\mathrm{dkbm}}$ is the discharging constraint of KiBaM; $P_{\text {misoc }}$ is the minimum capacity constraint; $\eta_{d}$ is discharging efficiency; $Q$ is the capacity before discharging; $Q_{1}$ is the capacity of the first tank before discharging; soc $_{\min }$ is the state of charge constraint; and $Q_{\max }, k$, and $c$ are the coefficients of $\mathrm{KiBaM}$, of which $Q_{\max }$ is the total capacity, $k$ is the ration of the first tank's capacity to the total capacity, and $c$ is the energy converting speed between the two tanks.

3.2. Modeling Considering Direct Load Transfer. As discussed above, the value of LSC is influenced by the strategy of load transfer. In this paper, the main strategy is divided into direct load transfer and indirect load transfer.

3.2.1. Direct Load Transfer. When N-1 contingency occurs, loads impacted by the failure can only be transferred to the transformers inside a substation and the transformers that have direct feeder connection with the failed transformer.

3.2.2. Indirect Load Transfer. When N-1 contingency occurs, the load transfer will be divided into 2 steps. In the first step, load impacted by the failure can be transferred to the transformers in the same substation and the transformers that have direct feeder connections with the failed transformer. The functional transformers in the substation can overload for a short time (usually a few hours) defined by a coefficient $k$, called overloading factor. In the second step, the overloaded loads need to be transferred to the transformers that have direct feeder connection with the overloaded transformers. The process of the 2 load transfer strategies is shown in Figure 2.

The overloading factor and duration are influenced by the manufacturing techniques of transformers, the top oil temperature of the transformers, and the operation guidelines.

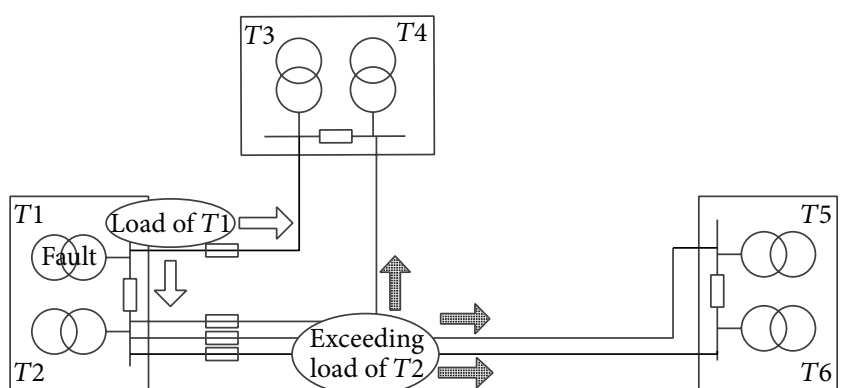

$\Longrightarrow$ Direct transfer

Indirect transfer

Figure 2: The process of the 2 transfer strategies.

TABLE 1: The overloading factor and duration.

\begin{tabular}{lc}
\hline $\begin{array}{l}\text { Overloading factor } \\
(\%)\end{array}$ & $\begin{array}{c}\text { Overloading duration } \\
\text { (minute) }\end{array}$ \\
\hline 110 & 180 \\
120 & 150 \\
130 & 120 \\
140 & 45 \\
150 & 15 \\
\hline
\end{tabular}

In the operation guideline of China, the overloading factor and duration are shown in Table 1 when the oil temperature is lower than $85^{\circ} \mathrm{C}$. In this paper, the overloading factor $k$ is taken as 1.3.

According to the strategy of direct load transfer, the model of LSC is established in formulae (6)-(9). The constants and variables used are listed in Table 2. Consider

$$
\begin{aligned}
& \max \quad \operatorname{LSC}=R^{T} \times T \\
& \text { s.t. } \quad \operatorname{diag}(R) \times T \leq \operatorname{Tr} \times Y+D \\
& \operatorname{Tr} \leq Y \times Y^{T} \times \operatorname{diag}(R) \times[E-\operatorname{diag}(T)] \\
& \operatorname{Tr} \leq C .
\end{aligned}
$$

In the model, formula (7) is the constraint of $\mathrm{N}-1$ contingency to insure that the loads impacted by failure can all be transferred. Formula (8) is the constraint of transformers to insure that no transformers will be overloaded. Formula (9) is connection feeder constraint to insure that no connection feeders will be overloaded.

3.3. Modeling Considering Indirect Load Transfer. Under indirect load transfer, the model of LSC is established in the following formulae:

$$
\begin{array}{ll}
\max & \mathrm{LSC}=R^{T} \times T \\
\text { s.t. } & \operatorname{diag}(R) \times T \leq \operatorname{Tr} \times Y+D
\end{array}
$$


TABLE 2: Constants and variables in the model.

\begin{tabular}{lllll}
\hline Symbol & Data type & Variable type & Dimension & Description \\
\hline$n$ & Number & Constant & 1 & Transformer number \\
\hline$T$ & Vector & Constant & $n \times 1$ & $\begin{array}{l}\text { Transformer capacity } \\
R_{i} \text { is capacity of the } i \text { th transformer }\end{array}$ \\
\hline$T r$ & Vector & State variable & $n \times 1$ & $\begin{array}{l}\text { Transformer loading factor } \\
T_{i} \text { is loading factor of the } i \text { th transformer }\end{array}$ \\
\hline$C$ & Matrix & Free variable & $n \times n$ & $\begin{array}{l}\text { Load transfer capacity } \\
\text { Tr } \\
\text { the } \text { is the load transfer capacity from the } i \text { th transformer to }\end{array}$ \\
\hline$D$ & Matrix & Constant & $n \times n$ & $\begin{array}{l}\text { Connection feeder capacity } \\
C_{i, j} \text { is the maximum load transfer capacity that connection } \\
\text { feed between the } i \text { th and } j \text { th transformer provides }\end{array}$ \\
\hline$Y$ & Probabilistic vector & Constant & $n \times 1$ & $\begin{array}{l}\text { DG route capacity } \\
D_{i} \text { is the total DG route capacity of the } i \text { th transformer }\end{array}$ \\
\hline & Matrix & Constant & $n \times n$ & Identity matrix \\
\hline
\end{tabular}

$$
\begin{aligned}
& \operatorname{Tr} \leq Y \times Y^{T} \times \operatorname{diag}(R) \times[E-\operatorname{diag}(T)] \\
& \operatorname{tr}_{i j}=\operatorname{tr}_{i 0 j}+\sum_{l} \operatorname{tr}_{i l j}, \quad \forall i, \forall j \\
& \operatorname{Tr}^{(0)} \leq C \\
& \sum_{j} \operatorname{tr}_{i l j} \leq(k-1) R_{l}, \quad \forall i, \quad \forall l \\
& \operatorname{tr}_{i l j} \leq c_{l j}, \quad \forall i, \forall j, \quad \forall l,
\end{aligned}
$$

where the matrix of load transfer capacity is divided into $\operatorname{Tr}^{(0)}$ that represents direct load transfer and $\operatorname{Tr}^{(2)}$ that represents indirect load transfer. In $\operatorname{Tr}^{(0)}=\left(\operatorname{tr}_{i 0 j}\right)_{n \times n}, \operatorname{tr}_{i 0 j}$ is the load transfer capacity from the $i$ th transformer to the $j$ th transformer when the $i$ th transformer fails. $\operatorname{Tr}^{(2)}=\left(\operatorname{tr}_{i l j}\right)_{n \times n \times n}$ is a 3 -dementional matrix. Element $\operatorname{tr}_{i l j}$ is the $l$ th transformer transformer's overloading capacity transferred from the $i$ th transformer. This part of capacity will be finally transferred to the $j$ th transformer because no transformer is permitted to overload for long term.

In this model, formula (13) divides the load transfer capacity between 2 transformers into direct load transfer capacity and indirect load transfer capacity. $\operatorname{tr}_{i 0 j}$ refers to the loads transferred to the $j$ th transformer through direct breaker actions when $\mathrm{N}-1$ contingency occurs on the $i$ th transformer. $\operatorname{tr}_{i l j}$ refers to the loads transferred to the $l$ th transformer in the same substation which is caused to overload. The overloaded loads $\operatorname{tr}_{i l j}$ are finally transferred to the $j$ th transformer through indirect load transfer. All the overloaded loads which finally are transferred to the $j$ th transformer are added together when there are more than one transformer in the substation that the $i$ th transformer belongs to. Formula (15) is introduced to insure that the loading of the overloaded transformer in the substation is constrained by the overloading factor. It means that the total loads of the $l$ th transformer are confined by the overloading factor.

These two models can determine, when the LSC reach the maximum, which transformers the loads can be transferred to and how many loads should be transferred.

3.4. Calculation Flow. The model of LSC is linear but with random variables. The method combining simple and point estimate methods is used to resolve this problem. The calculation flow is shown in Figure 3.

\section{Case Study of DG Configuration}

Taking the base case shown in Figure 4 as an example, the impact of DGs on LSC of the system is studied with different DG configurations. In the study, the control strategy of the battery is circling charging-discharging. In Figure 4, the lines between any 2 transformers are not real feeders but connection relationship. It is decided by connection feeder's capacity which is the summation of all feeders' load transfer capacity between any 2 transformers.

The transformer capacities and connection feeder capacities of the base case are provided in Table 3. Any numbers in the table represents the transfer capacity between two transformers. For example, the number 8 in column 3 row 2 means the connection feeder capacity between transformer 2 and transformer 3 is $8 \mathrm{MVA}$, which is the maximum load transfer capacity between these two transformers.

In the base case, there are five feeders to which the DGs are connected. The configuration of DGs in the feeders of transformer 1 is shown in Figure 5. The configurations of other DGs are not provided here since they are similar to those in Figure 5. In the figure, one of the DGs can indicate a single wind turbine, a single SPV, a single battery, or a combination of them. In the following study, the details of capacity, sites, and type of DGs will be changed in order to investigate their impact on LSC. 


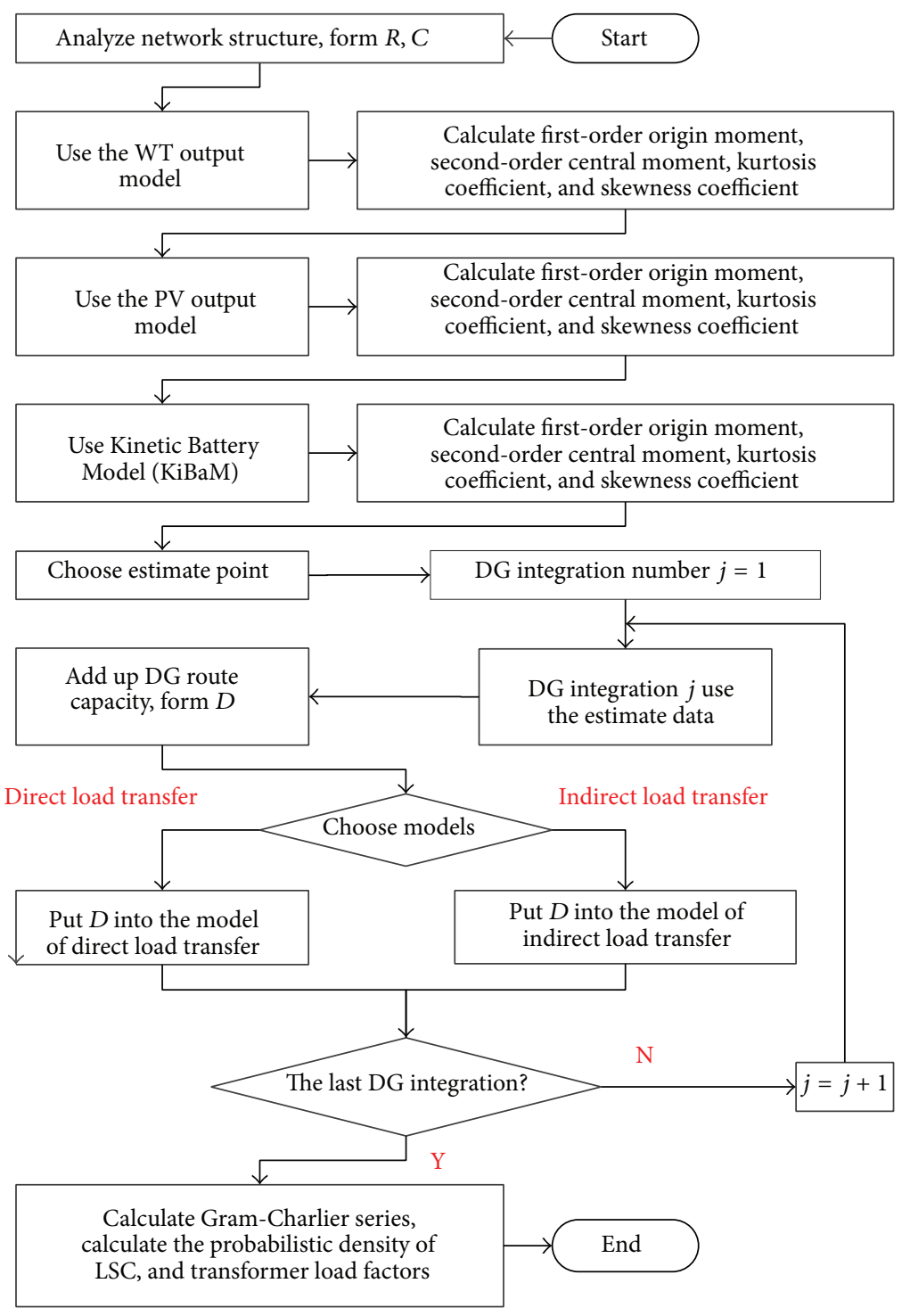

FIgURE 3: Calculation flow of LSC with DGs.

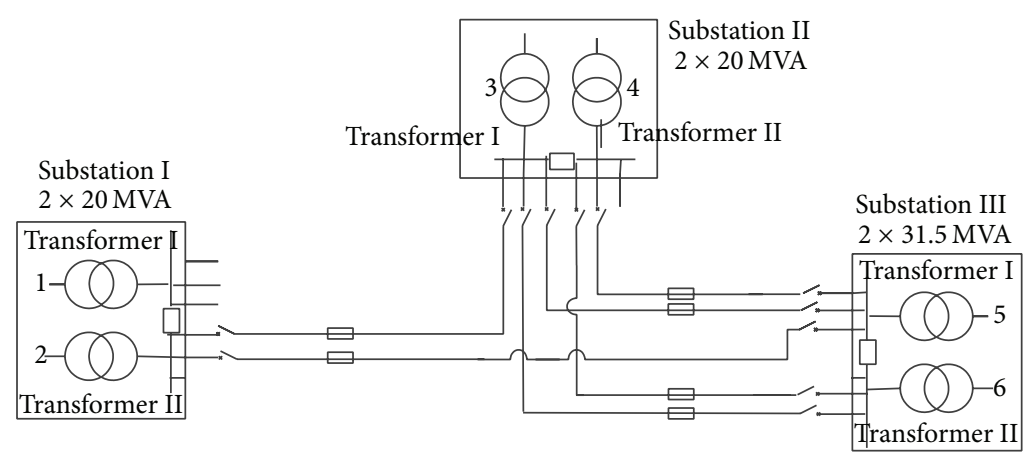

FIGURE 4: Connection structure of MV network in the case. 
TABLE 3: Capacities of the transformers and connection feeders.

\begin{tabular}{|c|c|c|c|c|c|c|}
\hline \multirow{2}{*}{$\begin{array}{l}\text { Connection feeder capacity } \\
\text { MVA }\end{array}$} & Tran. 1 & Tran. 2 & Tran. 3 & Tran. 4 & Tran. 5 & Tran. 6 \\
\hline & $20 \mathrm{MVA}$ & 20 MVA & $20 \mathrm{MVA}$ & $20 \mathrm{MVA}$ & 31.5 MVA & 31.5 MVA \\
\hline \multicolumn{7}{|l|}{ Tran. 1} \\
\hline $20 \mathrm{MVA}$ & 0 & 20 & 0 & 0 & 0 & 0 \\
\hline \multicolumn{7}{|l|}{ Tran. 2} \\
\hline 20 MVA & 20 & 0 & 8 & 0 & 3 & 0 \\
\hline \multicolumn{7}{|l|}{ Tran. 3} \\
\hline 20 MVA & 0 & 8 & 0 & 20 & 5 & 3 \\
\hline \multicolumn{7}{|l|}{ Tran. 4} \\
\hline $20 \mathrm{MVA}$ & 0 & 0 & 20 & 0 & 5 & 5 \\
\hline \multicolumn{7}{|l|}{ Tran. 5} \\
\hline $31.5 \mathrm{MVA}$ & 0 & 3 & 5 & 5 & 0 & 31.5 \\
\hline \multicolumn{7}{|l|}{ Tran. 6} \\
\hline $31.5 \mathrm{MVA}$ & 0 & 0 & 3 & 5 & 31.5 & 0 \\
\hline
\end{tabular}
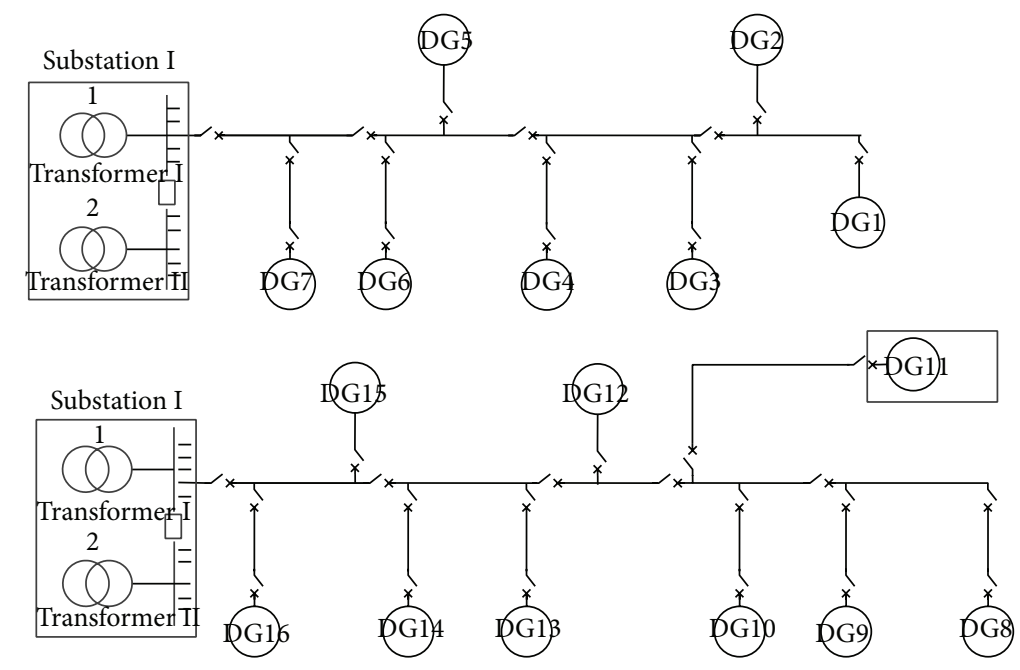

FIGURE 5: DGs integration in feeders of transformer 1.

4.1. Impact of Load Transfer Strategy. In this study, the impact of load transfer strategy is studied. A configuration of DGs shown in Table 4 is provided.

The calculation separately considers direct load transfer and indirect load transfer, where the results are shown in Table 5 .

According to Table 5, 97.5\% confidence interval of available transformer loading factors is achieved as shown in Figures 6 and 7.

DGs' intermittency causes the available loading factors to be probabilistic. In Figure 7, it is found that indirect load transfer not only increases LSC of the system but also attenuates the impact of DGs' intermittency on LSC. Obviously, the strategy of indirect load transfer is better and thus applied in the following study.

4.2. Impact of DGs' Sites. Based on the configuration in Figure 4, the impact is studied when the DGs are connected to different transformers in four cases. The first case is base

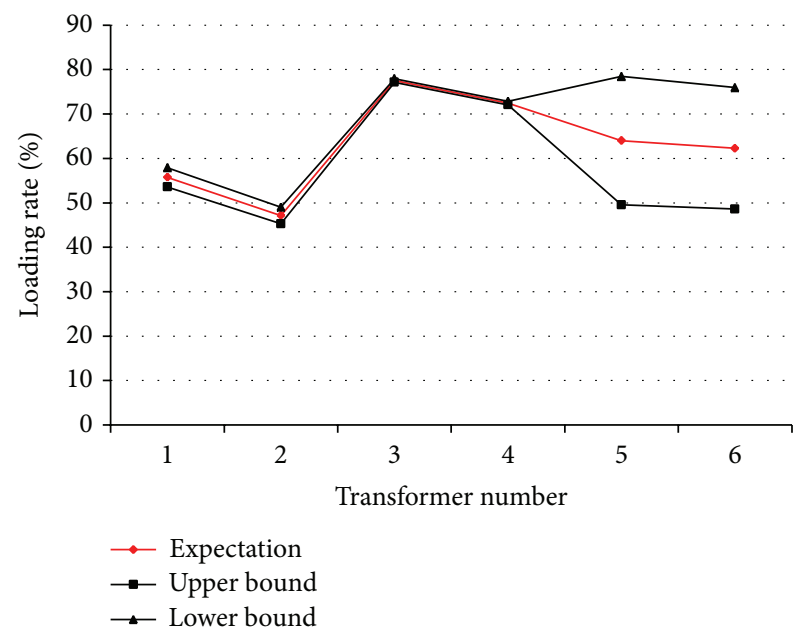

FIGURE 6: 97.5\% confidence interval of available transformer loading factors with direct load transfer strategy. 
TABLE 4: Installed capacities of DGs in feeders.

\begin{tabular}{|c|c|c|c|c|c|}
\hline Feeder & Transformer & DG integration & $\begin{array}{c}\text { Turbine capacity } \\
\text { kVA }\end{array}$ & $\begin{array}{c}\text { PV capacity } \\
\text { kVA }\end{array}$ & $\begin{array}{c}\text { Battery capacity } \\
\text { kVA }\end{array}$ \\
\hline Feeder 1 & 1 & 7 & 1685 & 1380 & 970 \\
\hline Feeder 2 & 1 & 9 & 2720 & 2010 & 1530 \\
\hline Feeder 3 & 2 & 7 & 2080 & 1200 & 1380 \\
\hline Feeder 4 & 5 & 7 & 2145 & 1500 & 970 \\
\hline Feeder 5 & 6 & 8 & 1965 & 1480 & 1170 \\
\hline
\end{tabular}

TABLE 5: Comparison between direct and indirect load transfer.

\begin{tabular}{lcccc}
\hline $\begin{array}{l}\text { LSC expectation } \\
\text { MVA }\end{array}$ & \multicolumn{2}{c}{$\begin{array}{c}\text { Direct load transfer } \\
90.3599\end{array}$} & \multicolumn{2}{c}{$\begin{array}{c}\text { Indirect load transfer } \\
101.143\end{array}$} \\
Tran. & $\begin{array}{c}\text { Loading factor } \\
\text { expectation }(\%)\end{array}$ & $\begin{array}{c}\text { Loading factor } \\
\text { standard deviation } \\
(\%)\end{array}$ & $\begin{array}{c}\text { Loading factor } \\
\text { expectation }(\%)\end{array}$ & $\begin{array}{c}\text { Londard deviation } \\
(\%)\end{array}$ \\
\hline 1 & 55.75 & 0.97 & 69.89 & 0.31 \\
2 & 47.16 & 0.84 & 63.02 & 0.39 \\
3 & 77.53 & 0.18 & 69.9 & 0.30 \\
4 & 72.47 & 0.18 & 75.53 & 0.38 \\
5 & 64 & 6.46 & 72.18 & 0.25 \\
6 & 55.75 & 0.97 & 72.18 & 0.00 \\
\hline
\end{tabular}

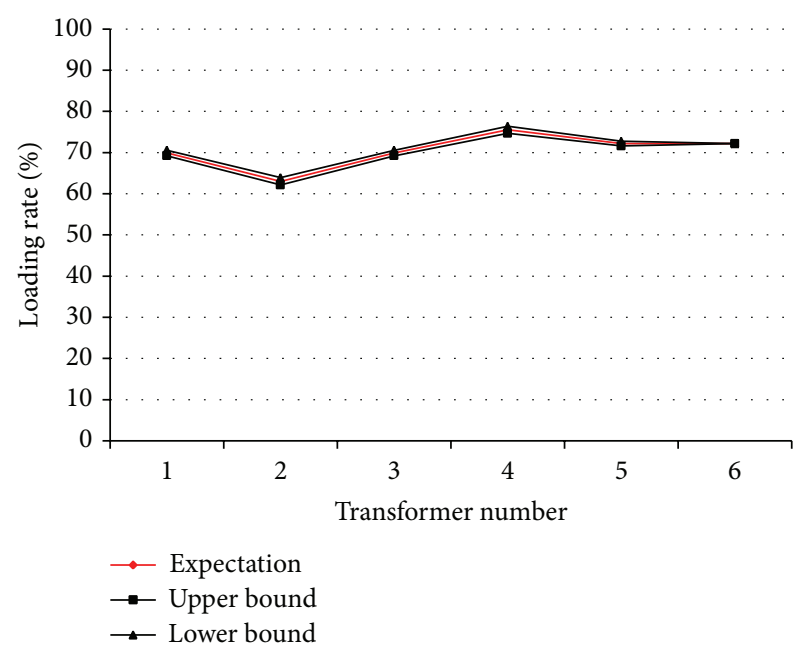

FIGURE 7: 97.5\% confidence interval of available transformer loading factors with indirect load transfer strategy.

case, where DG integration is shown in Table 4 . In the second case, all DGs are connected to transformer 1 which has fewer connection feeders. In the third case, all DGs are connected to transformer 3 which has more connection feeders. In the fourth case, all DGs are connected to transformer 6 which has larger capacity than transformer 3 . The results of these 4 cases are shown in Table 6, Figures 8 and 9, respectively.

The green column in Figure 8 shows that the amount of load the system has $80 \%$ probability to supply. Based on the results, it can be figured out that it is better for DGs to be connected to transformers with fewer connections. By

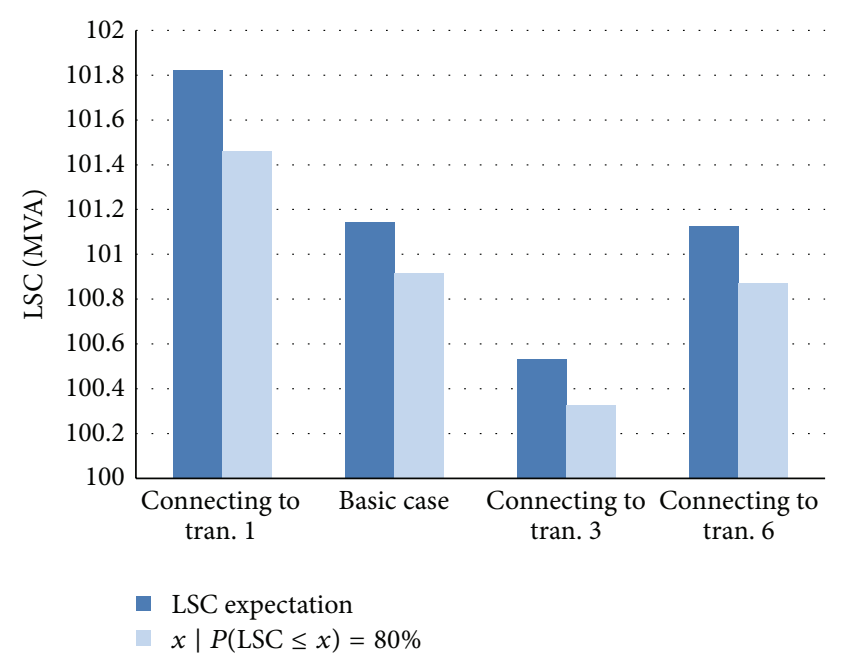

FIGURE 8: LSC expectation with different DG sites.

comparing cases 3 and 4, it is better for DGs to be connected to transformers which have larger capacity. Although in case 1 , the LSC increases to the highest extent, the increase is unstable as shown in Figure 9 due to large standard deviation.

4.3. Impact of DG Type. Based on the configuration in Figure 4, the impact is studied when the capacity ratio between wind turbines, photovoltaic panels, and batteries is changing. The percent of storage capacity increases from 0 to $100 \%$, with the total installed DG capacity unchanged. The results are shown in Figures 10 and 11. 
TABLE 6: The LSC with different DG sites.

\begin{tabular}{|c|c|c|c|c|}
\hline & Access to tran. 1 & Basic case & Access to tran. 3 & Access to tran. 6 \\
\hline $\begin{array}{l}\text { LSC expectation } \\
\text { MVA }\end{array}$ & 101.82 & 101.14 & 100.53 & 101.12 \\
\hline $\begin{array}{l}\text { LSC standard deviation } \\
\text { MVA }\end{array}$ & 0.33 & 0.14 & 0.04 & 0.23 \\
\hline $\begin{array}{l}x \mid P(\text { LSC } \leq x)=80 \% \\
\text { MVA }\end{array}$ & 101.45 & 100.91 & 100.32 & 100.87 \\
\hline
\end{tabular}

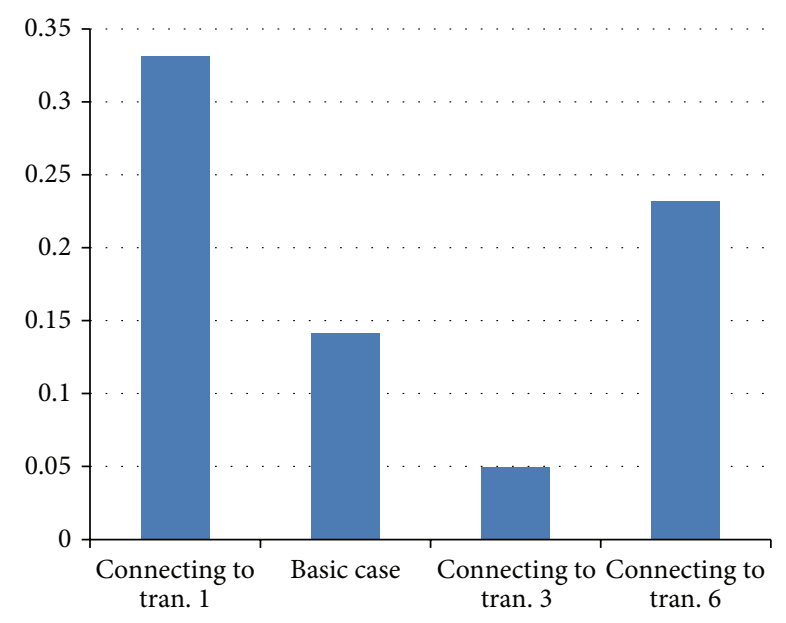

FIGURE 9: LSC standard deviation with different DG sites.

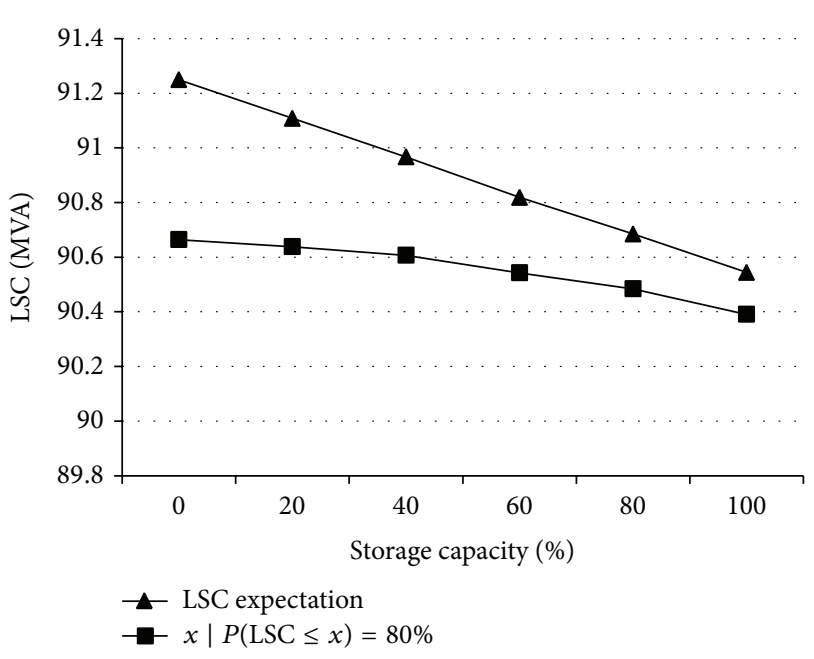

FIgURE 10: LSC expectation change trend with storage capacity.

Figure 10 shows that the LSC expectation decreases slightly when the percent of storage capacity increases. It is because different types of DGs have different efficiency of the LSC. In contrast, Figure 11 shows LSC standard deviation obviously decreases with more batteries. It proves that storage can contribute to the stableness of the LSC.

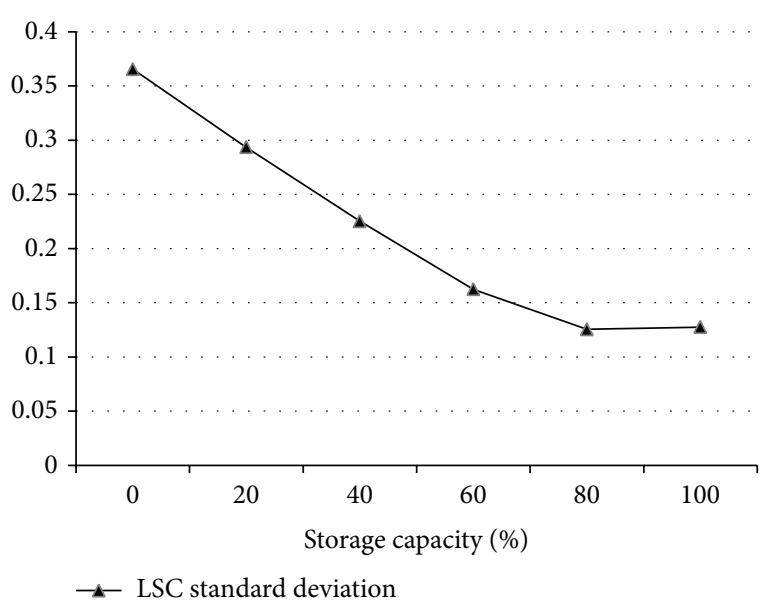

FIGURE 11: LSC standard deviation change trend with storage capacity.

\section{Conclusions}

In this paper, two LSC models in distribution power system considering DGs are proposed, with which the impact of DGs on LSC is studied. Through the analysis, the following conclusions are reached.

(1) DGs' integration increases system LSC. It is influenced by the strategies of load transfer. Indirect load transfer produces higher LSC and makes the incremental LSC more stable.

(2) It also proves that the transformers which the DGs are connected to have a direct impact on LSC. In order to make full use of LSC, DGs need to be connected to transformers which have fewer connection feeders and larger capacity.

(3) The study also illustrates that the more the storage in the system, the more stably the LSC increases. When the percent of storage capacity reaches around $80 \%$, the most stable incremental LSC can be achieved.

\section{Conflict of Interests}

The authors declare that there is no conflict of interests regarding the publication of this paper. 


\section{Acknowledgments}

This research is supported by Project of National Natural Science Foundation of China (Approval 51107085, 51261130473) and National High-Tech R\&D Program of China ("863" Program) (Approval 2011AA05A106). This research is also supported by Technology Project of State Grid CorporationActive Distribution System Technology and Application Research of Coordinated Planning for Large-Scale DG and Diversity Load Integration.

\section{References}

[1] S. Tan, J.-X. Xu, and S. K. Panda, "Optimization of distribution network incorporating distributed generators: an integrated approach," IEEE Transactions on Power Systems, vol. 28, no. 3, pp. 2421-2432, 2013.

[2] N. Jain, S. N. Singh, and S. C. Srivastava, "A generalized approach for DG planning and viability analysis under market scenario," IEEE Transactions on Industrial Electronics, vol. 60, no. 11, pp. 5075-5085, 2013.

[3] R. Razzaghi, M. Davarpanah, and M. Sanaye-Pasand, "A novel protective scheme to protect small-scale synchronous generators against transient instability," IEEE Transactions on Industrial Electronics, vol. 60, no. 4, pp. 1659-1667, 2013.

[4] N. R. Rahmanov, S.T. Ahmadova, and J. Bilbao, "Distributed generation system with renewable energy sources: grid modeling and simulation," in Proceedings of the IEEE EUROCON, pp. 984-991, Zagreb, Croatia, July 2013.

[5] K. N. Miu and H.-D. Chiang, "Electric distribution system load capability: problem formulation, solution algorithm, and numerical results," IEEE Transactions on Power Delivery, vol. 15, no. 1, pp. 436-442, 2000.

[6] F. Luo, C. Wang, J. Xiao, and S. Ge, "Rapid evaluation method for power supply capability of urban distribution system based on $N-1$ contingency analysis of main-transformers," International Journal of Electrical Power and Energy Systems, vol. 32, no. 10, pp. 1063-1068, 2010.

[7] S. Ge, J. Han, H. Liu, Y. Guo, and C. Wang, "Power supply capability determination considering constraints of transformer overloading and tie-line capacity," Proceedings of the Chinese Society for Electrical Engineering, vol. 31, no. 25, pp. 97-103, 2011.

[8] S. Zhang, H. Cheng, L. Zhang, M. Bazargan, and L. Yao, "Probabilistic evaluation of available load supply capability for distribution system," IEEE Transactions on Power Systems, vol. 28, no. 3, pp. 3215-3225, 2013.

[9] H. Liao, D. Liu, Y. Huang, and Y. Zhang, "Load transfer capability analysis considering interconnection of distributed generation and energy storage system," International Transactions on Electrical Energy Systems, vol. 24, no. 2, pp. 166-177, 2014.

[10] R. Karki, P. Hu, and R. Billinton, "A simplified wind power generation model for reliability evaluation," IEEE Transactions on Energy Conversion, vol. 21, no. 2, pp. 533-540, 2006.

[11] C.-S. Wang, H.-F. Zheng, Y.-H. Xie, and K. Chen, "Probabilistic power flow containing distributed generation in distribution system," Automation of Electric Power Systems, vol. 29, no. 24, pp. 39-44, 2005.

[12] J. Park, W. Liang, J. Choi, A. A. El-Keib, M. Shahidehpour, and R. Billinton, "A probabilistic reliability evaluation of a power system including solar/photovoltaic cell generator," in
Proceedings of the IEEE Power and Energy Society General Meeting (PES '09), pp. 1-6, Calgary, Canada, July 2009.

[13] J. F. Manwell and J. G. McGowan, "Lead acid battery storage model for hybrid energy systems," Solar Energy, vol. 50, no. 5, pp. 399-405, 1993.

[14] T. Lambert, P. Gilman, and P. Lilienthal, "Micropower system modeling with HOMER," in Integration of Alternative Sources of Energy, pp. 379-418, Wiley-IEEE Press, New York, NY, USA, 2006. 


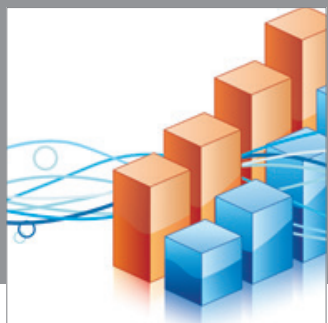

Advances in

Operations Research

mansans

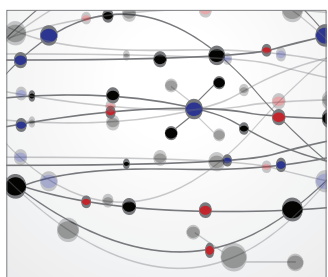

The Scientific World Journal
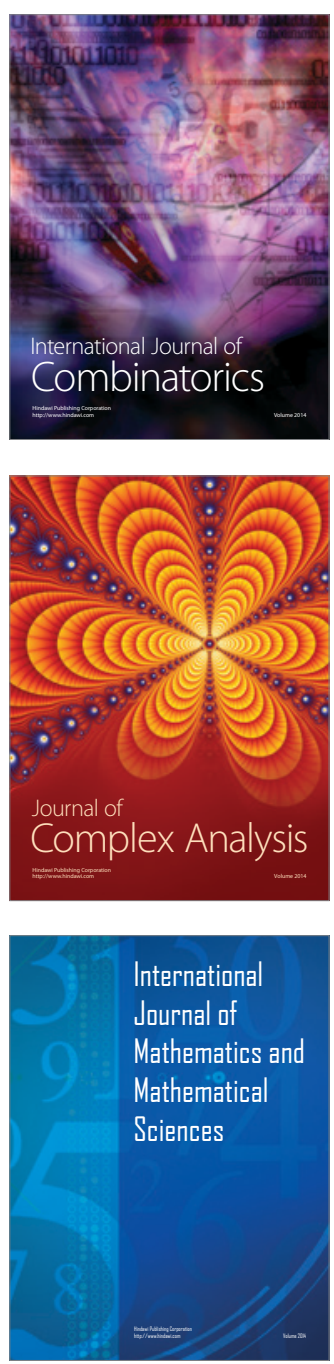
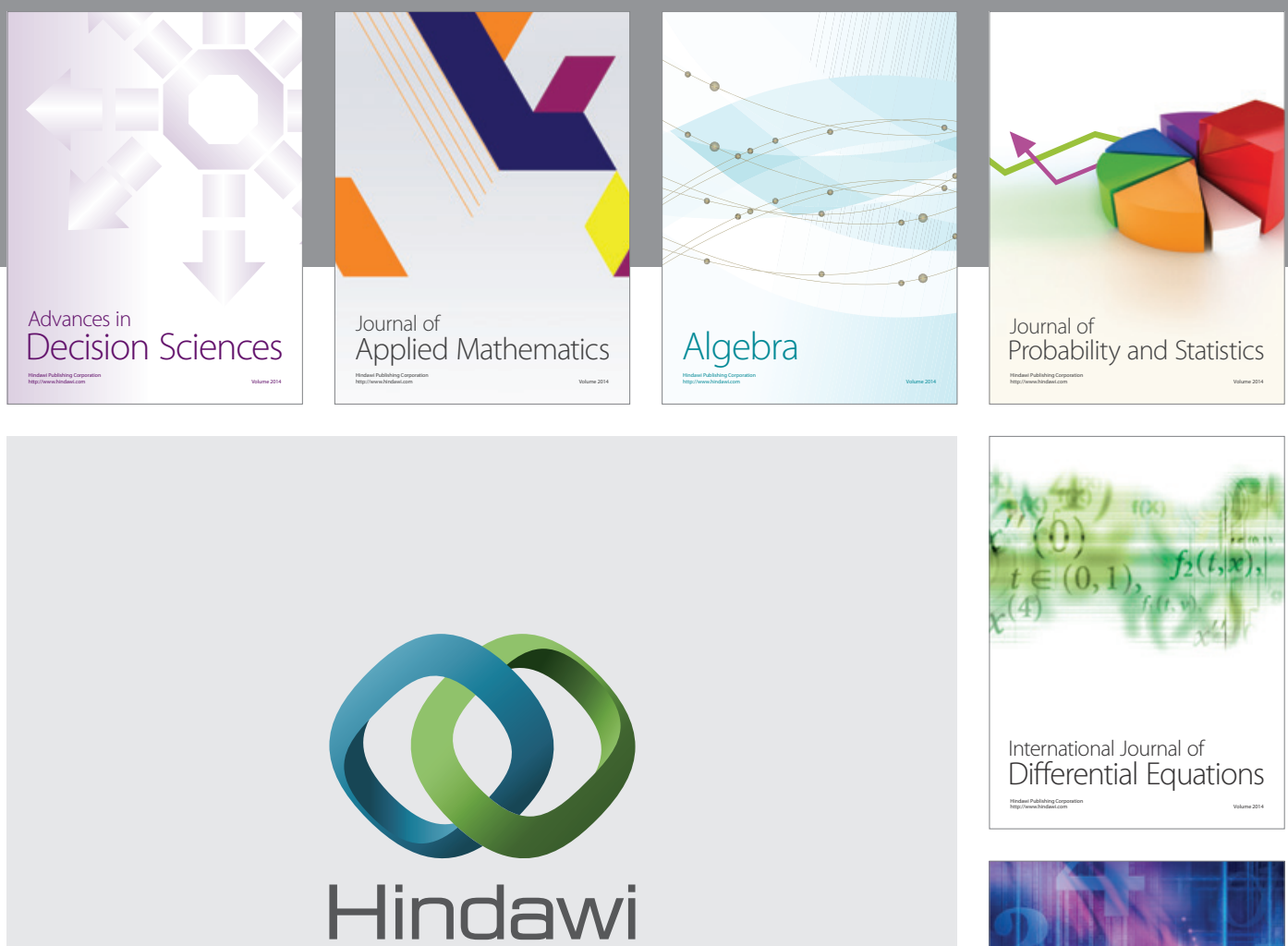

Submit your manuscripts at http://www.hindawi.com
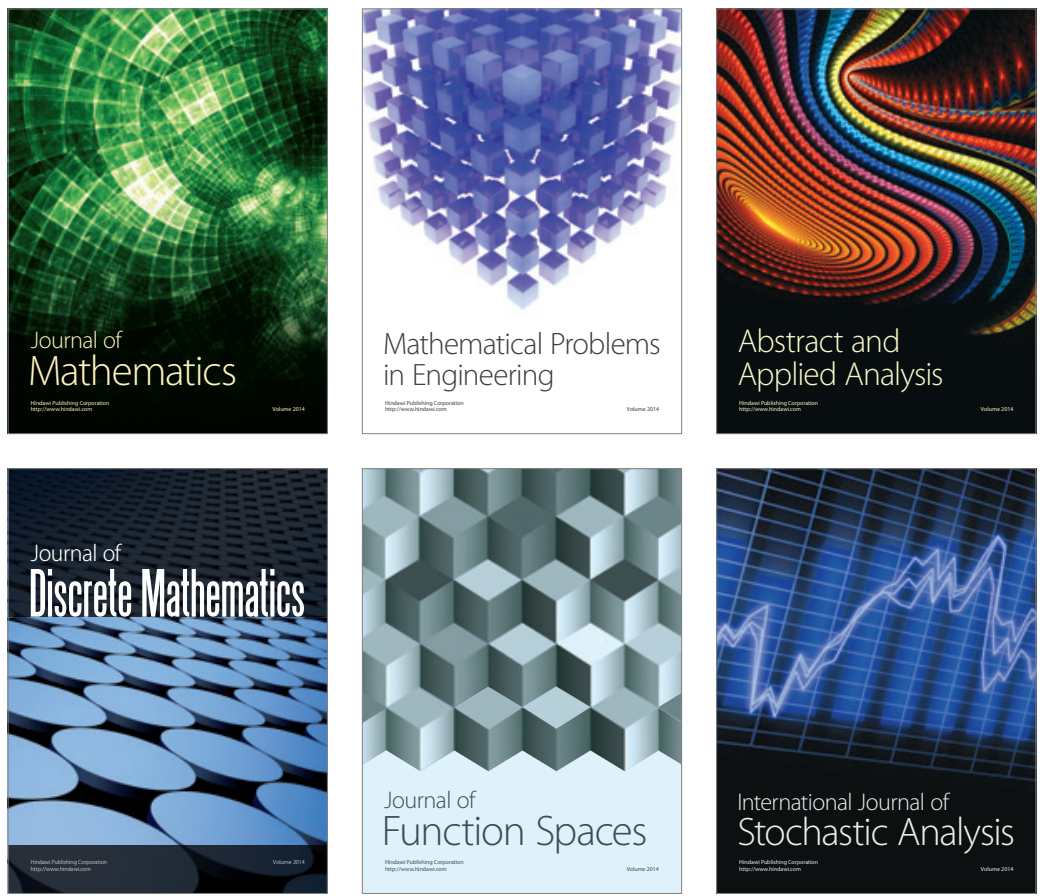

Journal of

Function Spaces

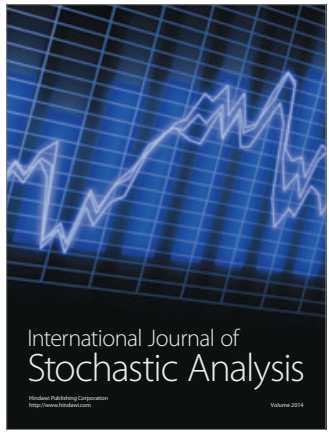

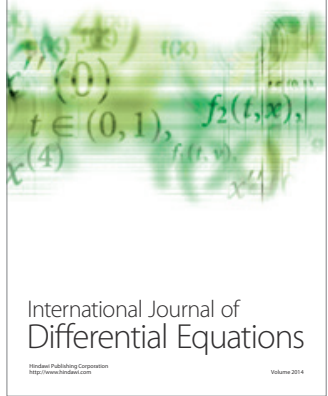
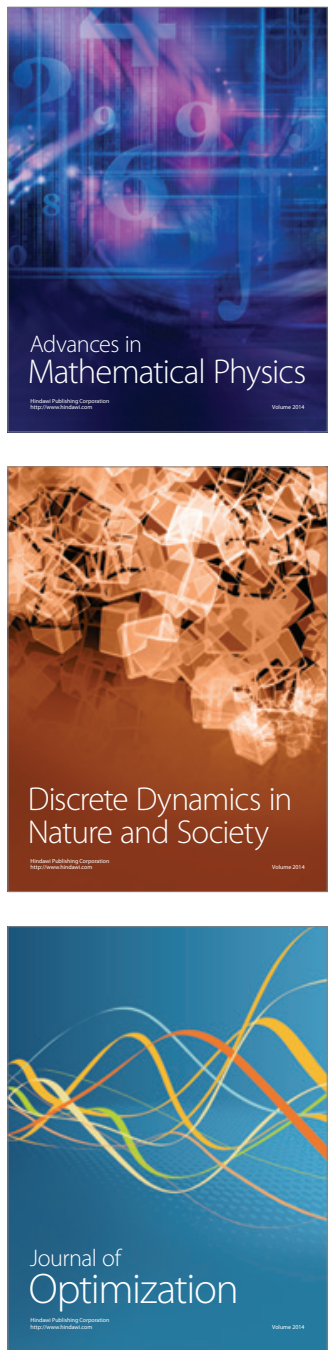